ISSN 2661-2666( Online) International Scientific Journal “Monte" DOI : $\underline{10.33807 / m o n t e .1 .201904219}$

ISSN 2661-264X (Print)

\title{
EDUCATION POLICY IN ALBANIA AND THE MAJOR PRINCIPLES OF THE PAN- EUROPEAN SOCIAL AND ECONOMIC RECOMMENDATIONS
}

Sub topic: Students at the centre of your working group in class

\section{EGLANTINA GJOKA}

“Eqerem Cabej”University Gjirokastra, Albania

“Deparment of Teaching and English Language,

\author{
Teacher of English Language, Abaz. Shehu School. Albania
}

\begin{abstract}
In Albania, efforts to create a more student-centered curriculum, expand the use of ICT, and increase equity have placed new expectations on teachers to create more inclusive classrooms where students develop transversal skills and prepare for participation in a democratic knowledge society. As Albania continues to decentralize its education system, school leaders are also expected to take on new responsibilities, reach out to parents, and build strong links with their communities. The main teacher and school leadership policy issues identified in this EPR include the status of the teaching profession, teachers' and principals' employment and working conditions, initial teacher preparation, the state examination and internship programmed that lead to teacher certification, hiring and deployment procedures, continuing professional development, teacher performance appraisal, and the school leadership role.
\end{abstract}

In highlighting these key policy issuesEducation policy in Albania draws upon some of the major principles of the pan-European social and economic recommendations, including those from the European Union and the Council of Europe, as well as several bilateral and multilateral organizations. In additional - although Albania is not a member of the OECD - the OECD's programmed for International Student Assessment (PISA), in which Albania has participated since 2000, has become a key point of reference for education policy-makers. Albania has become a signatory to a number of international and European covenants, conventions and recommendations directly or indirectly impacting the country's education sector.

Major conventions and agreements including the Bologna Declaration (signed in 2003); EU candidate status (granted in 2014); and Convention on the Rights of Persons with Disabilities (ratified in 2013) for example, provide a supra-national normative framework for Albania's educational reforms.

Learning standards are concise, written descriptions of what students are expected to know and be able to do at a specific stage of their education. The Law on Inclusive Education, adopted in 2012, guarantees the right of children with disabilities to education, and furthermore, access to special teaching personnel trained in catering to the special needs students may have. 
At the same time, there is significant evidence suggesting the highly constrained capacity of individual schools for the intake of children with disabilities (ADRA Albania, 2015).

The supply of schools for children with disabilities is rather limited in Albania with virtually nonexistent access to education in rural areas (De Soto et al., 2005, p. 58). The Government of Albania has committed to increase the enrolments of children with disabilities and children from impoverished families by $2 \%$ in PUE (Republic of Albania, 2013, p. 89).

It is anticipated that considerable infrastructure improvements and improved access to services for children with disabilities will result from adoption of the most recent framework law on inclusion of and accessibility for people with disabilities (European Commission, 2014, p. 37).Learning standards describe educational objectives, what students should have learned by the end of a course, grade level, or grade span but they do not describe any particular teaching practice, curriculum, or assessment method (although this is a source of ongoing confusion and debate).

Key words: Learning standards, Educational Objectives,State's department of education, educators and subject-area specialists, students and class, public-commentary periods, development, reforms.

JEL Classification System: SI, S2, S3, N0, N1, N2, N3, O1, O2, 03

\section{GENERAL INFORMATION AND PURPOSE OF THIS PAPER RESEARCH:}

Education policy in Albania draws upon some of the major principles of the pan-European social and economic recommendations, including those from the European Union and the Council of Europe, as well as several bilateral and multilateral organizations. In additional - although Albania is not a member of the OECD - the OECD's programmed for International Student Assessment (PISA), in which Albania has participated since 2000, has become a key point of reference for education policy-makers.

The analysis on curriculum development and reform highlights the following: curriculum reform must be incremental; widespread communication of reforms must reach a range of stakeholders; there must be support for local implementers as well as ongoing monitoring, formative evaluation and feedback mechanisms to make adjustments where needed. Furthermore, the EPR supports the further development of policies and practices that promote full inclusion for vulnerable students; teachers' professional development that enables them to create inclusive learning environments and flexible instruction to reach all learners; local contextualization of the curriculum materials and texts; and improvement to the overall alignment of the education system over the medium and long term of implementation

The education indicators can be difficult to calculate for a number of reasons. For certain indicators, such as the student to teacher ratio, you are required to include the local and overaged children with the refugee children. For other indicators, such as enrolment percentages, you are required to include just the school-aged refugee children. 
An additional challenge is that you are required to generate data on certain age groups which, depending on your operation, can be difficult to obtain (i.e. 15-24 year olds). The operational purpose of calculating the percentage of qualified or trained teachers is to assess the quality of education being provided to the students. Knowing the percentage of qualified teachers is particularly important in order to assess whether or not displaced children and adolescents are receiving quality education.

\subsubsection{Number of students per teacher}

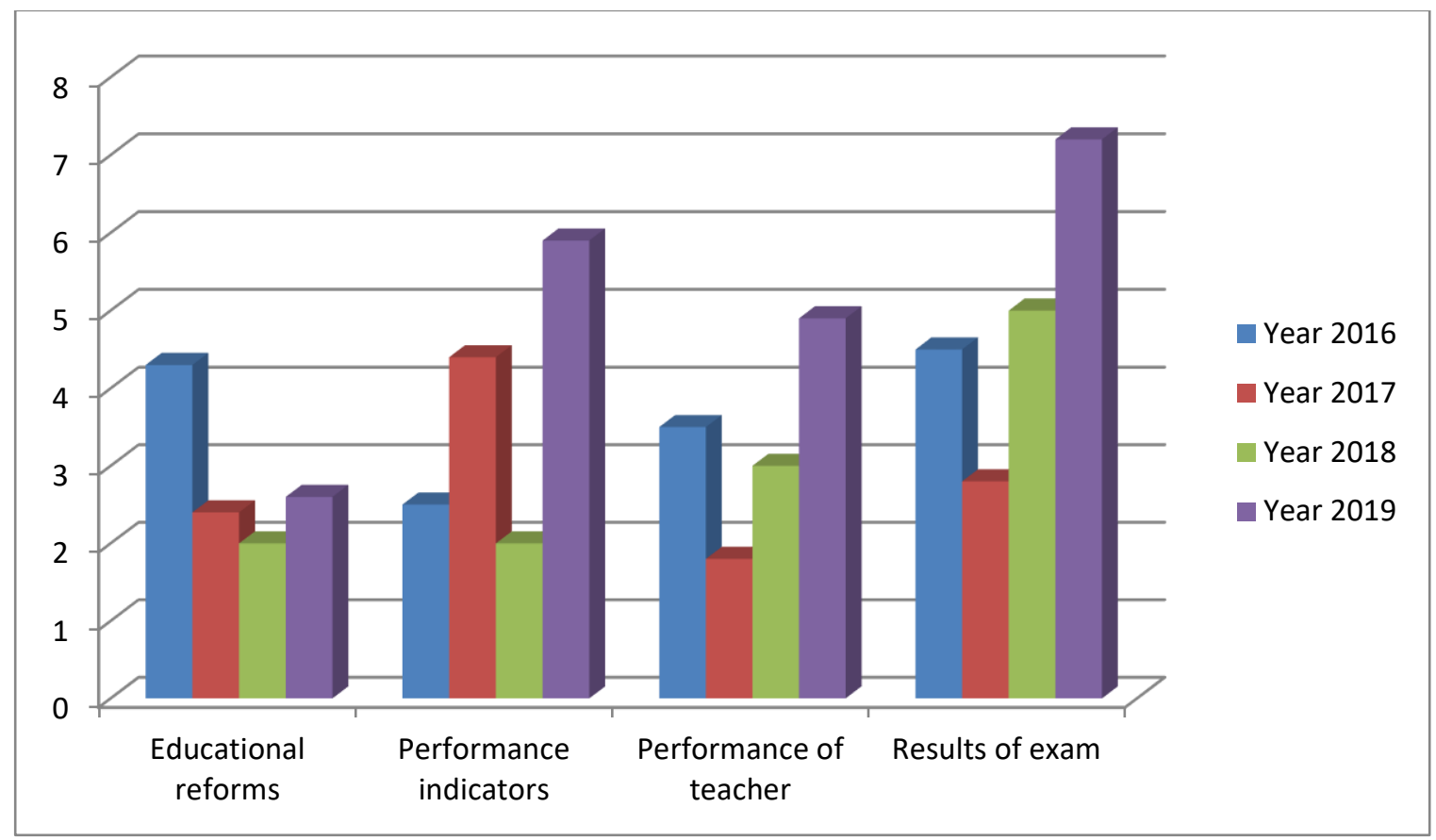

Evidence and Discussion Education policy in Albania draws upon some of the major principles of the pan-European social and economic recommendations, including those from the European Union and the Council of Europe, as well as several bilateral and multilateral organizations. In additional - although Albania is not a member of the OECD - the OECD's programmed for International Student Assessment (PISA), in which Albania has participated since 2000, has become a key point of reference for education policy-makers. Source: Order 418, dated 11.08.2016, on approval of regulation for professional development and qualification of heads of educational institutions in the pre-university education system

Unlike the enrolment indictors, this indicator requires that you include all students in the classroom (including over-aged and local children), not just school aged refugee children. (for example, child labor, forced military recruitment, childhood illness, or poor education programming).

However, if the camp population has drastically decreased in that month due to repatriation, you might find that the attendance rate of $78 \%$ is unchanged. If for example you had 336 students in the school and 14 teachers, your calculation will look like this: $336=24$ students per teacher 14 
similarly, if you are calculating student-to-textbook ratios, or student-to-desk ratios, you should include all children in the classroom, regardless of nationality or age.

\subsubsection{Calculating Education Indicators in Albanian schools}

The percentage of qualified teachers is determined by dividing the numerator, the total number of qualified and trained teachers, by the denominator, the total number of teachers. If for example there are 15 qualified or trained if your operation uses progress, you should be able to obtain the number of refugees in any given age group.

If you do not currently have access to progress data, it can be obtained by contacting the registration focal point in your operation. A good idea, especially when asked to report on indicators such as the 'percentage of 15-24 year olds enrolled in training,' is to create a filter in progress. Source: UNHCR Report 2017

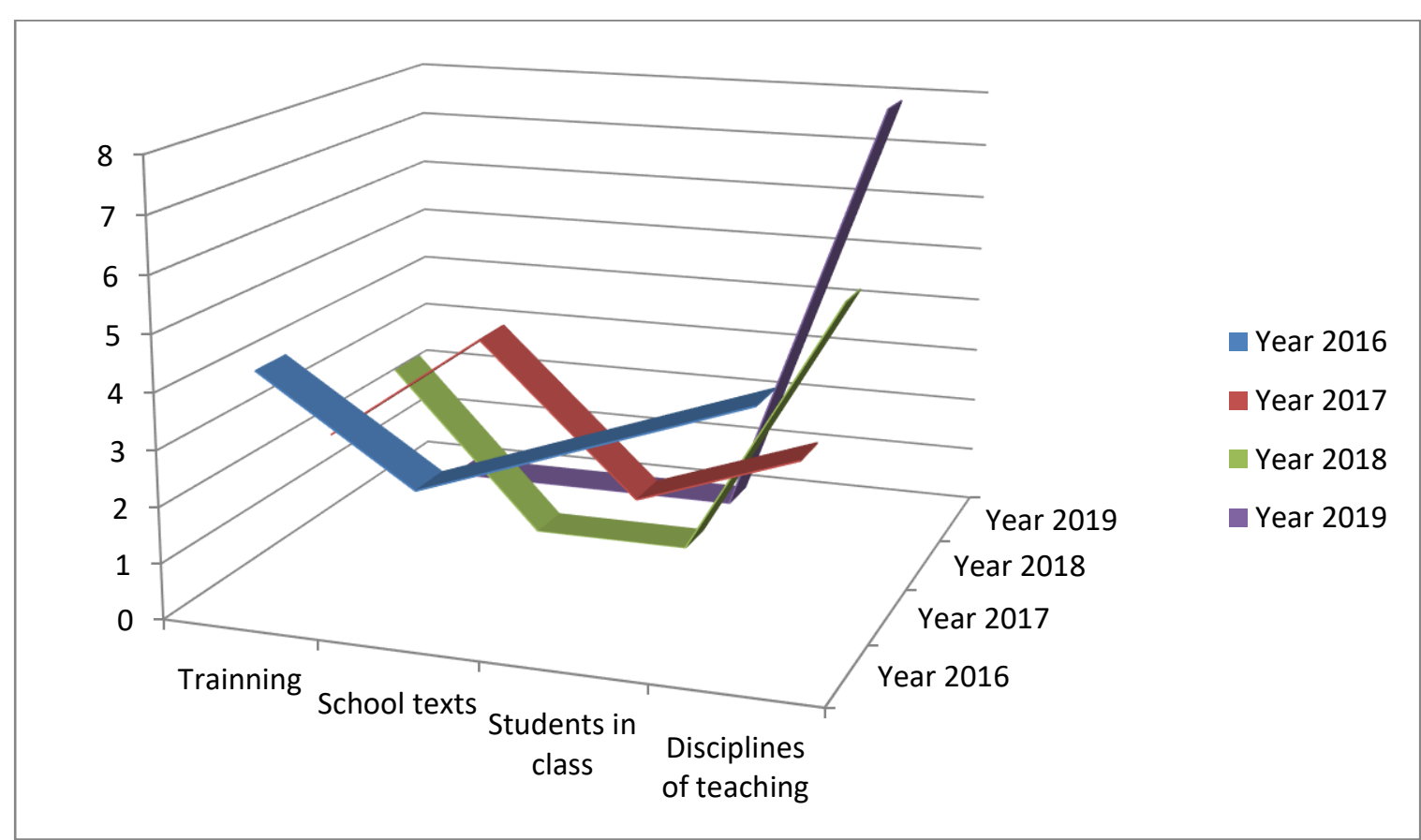

Source: UNHCR Report 2017

"For example, if the standard for primary enrolment is set at 100 per cent, but the indicator measures enrolment at only 70 per cent, there is a gap of 30 per cent. Sometimes due to cultural, geographic or other circumstances, it may not be possible for your area to achieve all of the standards. A similar process can be followed to calculate the percentage of qualified male teachers, and also what percentage of the teaching population is comprised of qualified male teachers.

1. Introduction time. Similarly, programming decisions that are not based on the indicators may not in fact target the largest education gaps, because these gaps have not been properly identified. Many questions are often asked when calculating education statistics for Standard and Indicator Reports, such as 'When do I include the local population? 
Why are enrolment percentages reaching over 100 per cent? Is gender parity the same as the percentage of girls enrolled in school?'

2. The education standard and indictor information is also important to secure funding from donors and potential donor countries and organizations.

3. If, for example, all of the countries in region A are reporting over 100 per cent enrolment and/or 100 per cent of qualified teachers, it would appear as if these countries are doing very well as regards access to and quality of education.

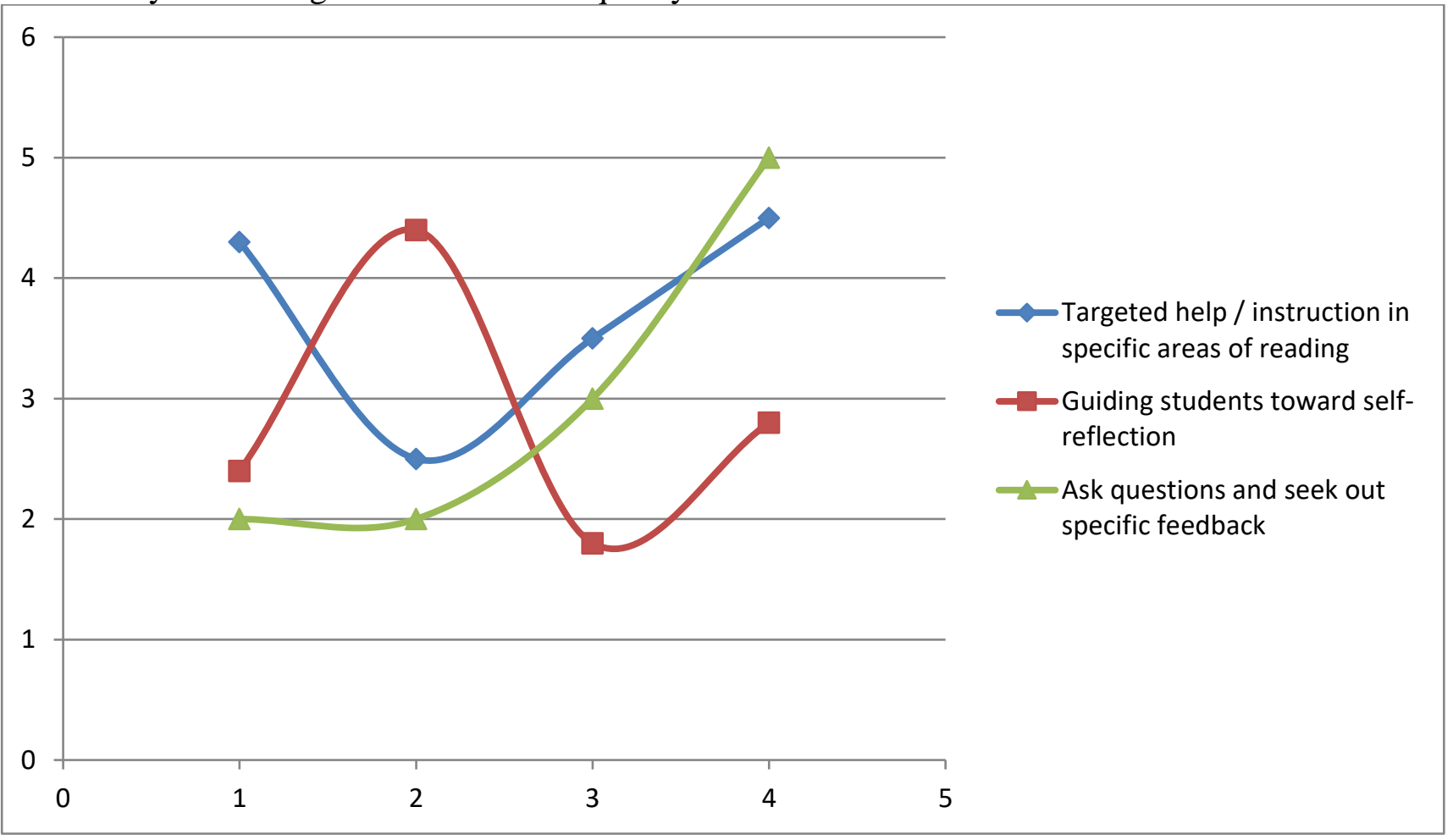

\section{Standards and Indicators and Other Key}

The education reform includes the development of digital competences. One of the main challenges' regarding the implementation of the reform related to school textbooks and teaching materials is the lack of proper infrastructure, particularly in the area of ICT. For this reason, the curriculum reform in Albania includes an initiative focusing on the use of ICT in education, which is further discussed in the next section.

To support the development of students' digital competences and to help teachers and students in the learning process, MES and IED are working to provide other learning resources, especially digital resources, for schools. Throughout the reform process, the collaborative learning process in schools is key. MES reports that there are departments in schools in which teachers collaborate in order to discuss and design syllabi and organize their classes. Burimi: Order 418, dated 11.08.2016, on approval of regulation for professional development and qualification of heads of educational institutions in the pre-university education system 
There is also an active process of peer observation and reflection sessions. The process for new textbook selection has also changed with the implementation of the reform. According to MES, new textbooks are new designed according to the curriculum programmers and they are competitively assessed according to the textbook standards by four evaluators. The winning textbooks are then piloted for one year before being certified by the publishers after reflecting on comments and feedback from the teachers who piloted the texts. This process should aid in increasing the relevance and alignment of new textbooks with the reformed curriculum in Albania.

\section{LITERATURE REVIEW AND HYPOTHESES}

According to UNICEF, school attendance is a major issue with both of these marginalized groups, yet the numbers of students not attending school is under-reported. The only hard data available for the UNESCO review team on children with disabilities was the number of students actually enrolled in schools.

However, interviewees highlighted that there are significant numbers of children who are not in school at all, and not acknowledged as being in need of education. Additionally, many Roma girls drop out school at the 5th year of education (age 10). Source: Order 418, dated 11.08.2016, on approval of regulation for professional development and qualification of heads of educational institutions in the pre-university education system.

Education policy in Albania draws upon some of the major principles of the pan-European social and economic recommendations, including those from the European Union and the Council of Europe, as well as several bilateral and multilateral organizations. In additional - although Albania is not a member of the OECD - the OECD's programmed for International Student Assessment (PISA), in which Albania has participated since 2000, has become a key point of reference for education policy-makers. 


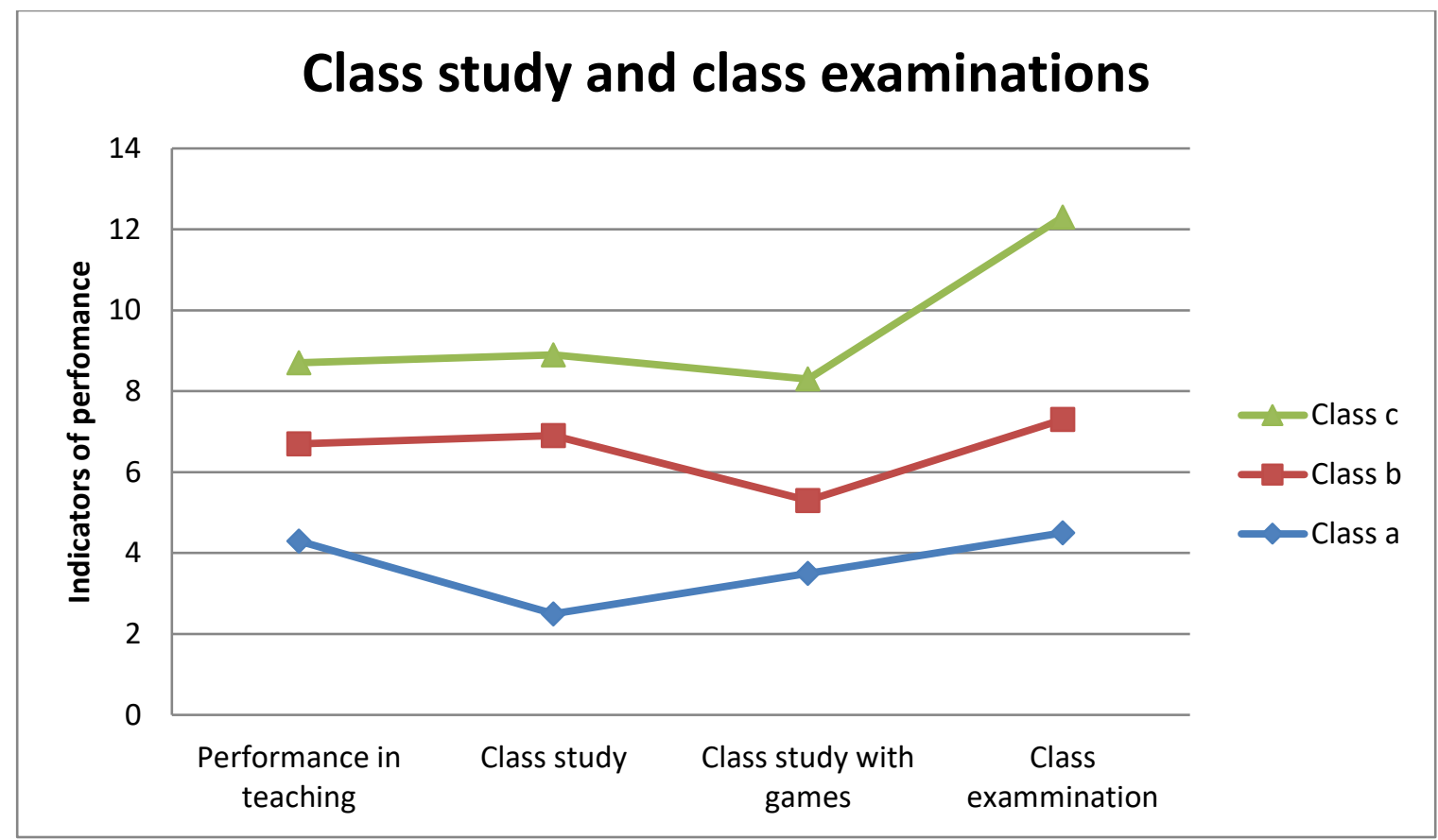

\section{COMMUNICATION IN YOUR CLASS}

The teacher keeps current on instructional knowledge and seeks and explores changes in teaching behaviors that will improve student performance. An effective student information management system should include yearly achievement, national assessment results, and other information relevant to the individual student. An effective system should be able to accumulate the relevant information on a student as he/she moves through the system, and perhaps from school to school or region to region. Feedback surveys should be developed centrally in consultation with the representative local participants

Quality Indicator 1: Classroom management techniques

Quality Indicator 2: Management of time, space, transitions, and activities

Quality Indicator 3: Classroom, school and community culture Standard

\section{Effective Communication}

The teacher models effective verbal, nonverbal, and media communication techniques with students, colleagues and families to foster active inquiry, collaboration, and supportive interaction in the classroom. 
ISSN 2661-2666( Online) International Scientific Journal “Monte" DOI : $\underline{10.33807 / m o n t e .1 .201904219}$ ISSN 2661-264X (Print)

\section{Evidence and Discussion on Albanian teaching reforms}

The development of clear and measurable targets and indicators is a crucial step in ensuring the success of Albania's education reforms. Enacting effective mechanisms for monitoring and evaluating the outcomes of reforms is also keys to ensuring success. The successful implementation of education reform in Albania requires coherent and sustained interventions. According to the UNESCO review team's analysis, the current policy and institutional architecture concerning ICT in education is too fragmented to meet evolving national aspirations and global demands

Furthermore, the review team recommends that administration needs to be streamlined and rationalized; data collection should be enhanced and better use made of data in policy making; and more attention needs to be given to strengthening capacity at the school level to address emerging needs. Additionally, equity must be put at the centre of all these reforms. National ICT policies in education will have the greatest impact if they are aligned with other strategic and operational policies, particularly those designed to enhance educational quality, equity, and inclusion: Burimi: Order 418, dated 11.08.2016, on approval of regulation for professional development and qualification of heads of educational institutions in the pre-university education system

Monitoring and formative evaluation during implementation provides useful feedback to education authorities, and can help teachers and principals in the schools see their progress. With reliable information, governments can more effectively target investments in training and resources, and make changes to implementation plans and guidelines if these are needed.

1. The teacher uses professional communication and interaction with the school community;

2. The teacher acts as a responsible professional in the overall mission of the school.

Quality Indicator 1: Verbal and nonverbal communication

Quality Indicator 2: Sensitivity to culture, gender, intellectual and physical differences

Quality Indicator 3: Learner expression in speaking, writing and other media

Quality Indicator 4: Technology and media communication tools

Encourage initial leadership training: Whether initial training is voluntary or mandatory can depend on national governance structures. Governments can define national programmers, collaborate with local level governments and develop incentives to ensure that school leaders participate.

\section{CONCLUSIONS}

Attracting highly qualified applicants to the teaching profession is thus a key area of policy concern in Albania. One possible approach to increasing the attractiveness of teaching would be an across-the-board increase to teachers' salaries. Burimi: Order 418, dated 11.08.2016, on approval of regulation for professional development and qualification of heads of educational institutions in the pre-university education system.

However, if teachers' salaries in Albania are already high compared to comparable public professions, a salary increase would need to be substantial in order to have an impact on the 
attractiveness of the teaching profession as a whole. The government will need to weigh the relative costs and benefits of teacher salary increases and determine whether the increased salaries would have an overall positive effect on the attractiveness of the profession

Learning progressions: In each subject area, standards are typically organized by grade level or grade span-consequently, they may be called grade-level expectations or grade-level standards - and the sequencing of standards across grades or stages of academic progress is called a "learning progression" (although terminology may vary from place to place). Learning progressions map out a specific sequence of knowledge and skills that students are expected to learn as they progress through their education. Burimi: Order 418, dated 11.08.2016, on approval of regulation for professional development and qualification of heads of educational institutions in the preuniversity education system

To be able to monitor student achievement effectively, in a world where students may move from school to school, or may leave school, requires a robust national system for managing student information, from enrolment to achievement.

1. Implement the Higher Education Reform, with a particular focus on the education of candidate teachers, and develop a national system to monitor the ongoing development of pre- and in-service teachers' ICT skills.

2. Collaborate with international donors in order to design and implement continuing professional development initiatives aimed at training in-service teachers, and ICT teachers in particular, in the use of ICT for educational purposes.

3. Encourage collaboration among teachers and school leaders with different levels of expertise in the use of ICT for teaching and learning purposes.

4. There are jurisdictions that have implemented effective systems, which may be willing to share their expertise and advice - this could help to speed and streamline Albania's work.

5. In the intervening period, provision should be made for each school to improve the data it collects on a daily basis in a less technologically sophisticated way that might have sufficient consistency to be used as indicators.

There are two main characteristics of learning progressions: (1) the standards described at each level are intended to address the specific learning needs and abilities of students at a particular stage of their intellectual, emotional, social, and physical development, and (2) the standards reflect clearly articulated sequences - that is, each grade-level learning expectation builds upon previous expectations while preparing students for more challenging concepts and more sophisticated coursework at the next level.

The basic idea is to make sure that students are learning age-appropriate material (knowledge and skills that are neither too advanced nor too rudimentary), and that teachers are sequencing learning effectively or avoiding the inadvertent repetition of material that was taught in earlier grades. For a more detailed discussion, see learning progression. 


\section{REFERENCES}

- Udhëzim 4, datë 19.02.2015 për një ndryshim në udhëzimin Nr. 2, datë 12.02.2015 'për kriteret dhe procedurat e kualifikimit të mësuesve' [Administrative Instruction 4, dated 19.02.2015, on changes to Administrative Instruction 2, dated 12.02.2015, 'on criteria and procedures for the qualifications of teachers']. http://www.klasavirtuale.com/

- Udhëzim 38, datë 06.10.2015 [Administrative Instruction 38, dated 06.10.2015, on the transfer, appointment and dismissal of teachers employed in the public education institutions of the pre-university education system]. http://www.arsimi.gov.al/files/userfiles/apu/

- Udhezimi_nr.38_per_publikim_(1).pdf (Accessed 12 October 2015.) (in Albanian.)

- [Order no. 421, date 04.11.2015 "For the training agencies that have been accredited training programs/modules in the past]. (in Albanian).

- Urdhër Nr. 418, datë 11.08.2016

- [Order 418, dated 11.08.2016, on approval of regulation for professional development and qualification of heads of educational institutions in the pre-university education system]. (in Albanian).

- Principals of high-achieving schools are confident that their schools can meet their goals (Cotton, 2003).

- Principals who focus on school improvement have more effective schools (Shen \& Hsieh, 1999).

- Principals of high-achieving schools communicate to all stakeholders that learning is the school's most important mission (Cotton, 2003; Marzano et al., 2005)

- John Day, 1946; revised edition, 1972. Title of British edition: Big Business. London: Heinemann, 1946.

- Drucker, Peter F. The New Society. New York: Harper \& Row, 1950.

- Eells, R.S.F. and Walton, C.C. Conceptual Foundations of Business. Homewood, Ill.: Irwin, 1961.

- Emmett, Boris, and Jeuck, John C. Catalogues and Counters; A History of Sears, Roebuck \& Co. Chicago: University of Chicago, 1950.

Predictive validity of the performance assessment for California teachers. Stanford, CA: Stanford Center for Opportunity Policy in Education. Retrieved from http://scale.stanford. edu/;

Wilson. M., \& Hallum, P. J. (2006). Using student achievement test scores as evidence of external validity for indicators of teacher quality: Connecticut's Beginning Educator Support and 